Supporting Information

\title{
Direct Analysis of Non-Volatile Chemical Compounds on Surfaces \\ Using a Handheld Mass Spectrometer with Synchronized Discharge Ionization Function
}

\author{
Xiao Wang ${ }^{1}$; Xiaoyu Zhou ${ }^{1}$; Zheng Ouyang ${ }^{1,2,3^{*}}$
}

${ }^{1}$ Weldon School of Biomedical Engineering, ${ }^{2}$ Department of Electrical and Computer Engineering and ${ }^{3}$ Department of Chemistry, Purdue University, West Lafayette, IN, 47907, USA

\section{Prepared for AC}

*Corresponding Author

Zheng Ouyang, Email: ouyang@purdue.edu. Phone: (765) 494-2214. Fax: (765) 496-1912. 


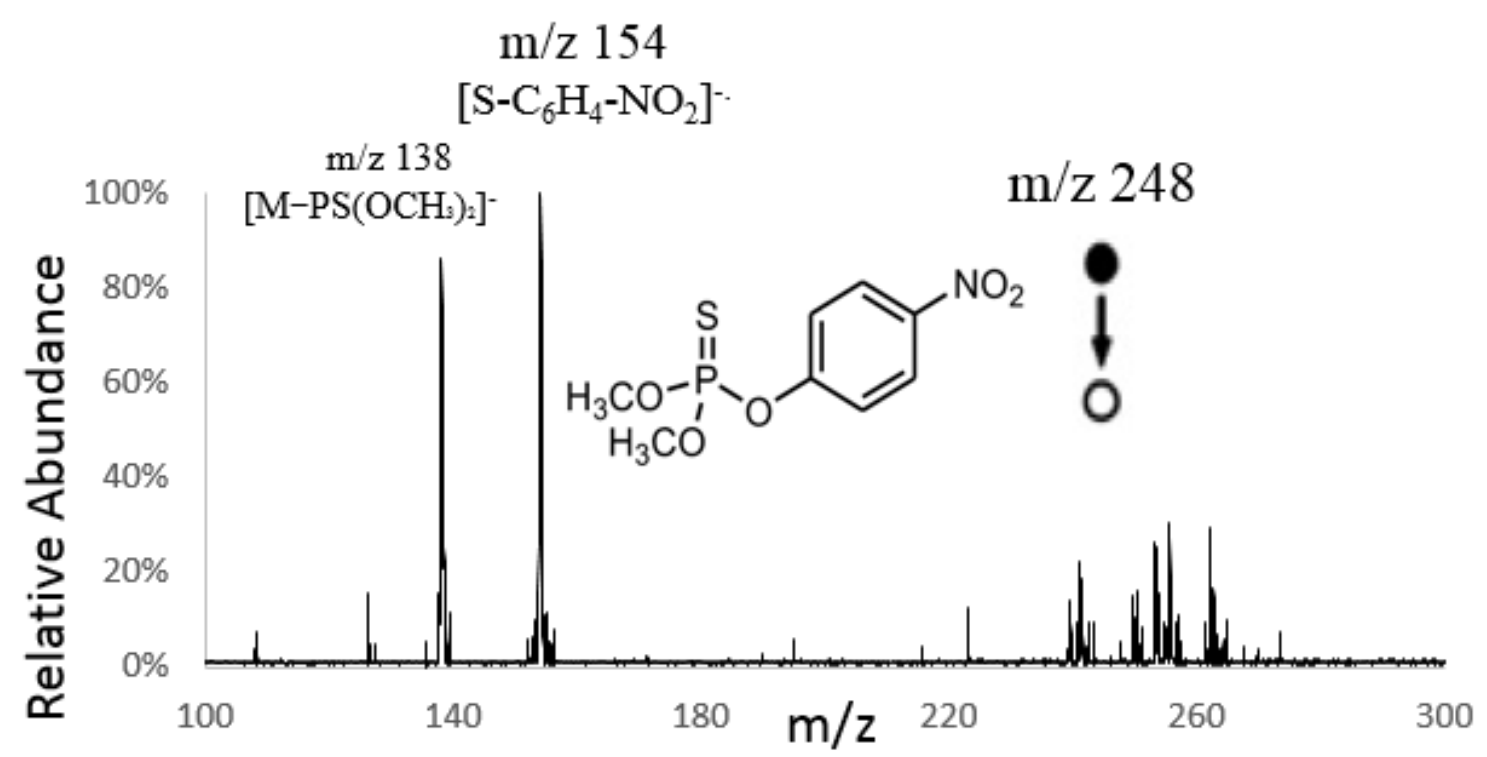

Figure S1. MS/MS Spectrum of 300 ng of parathion-methyl detected on a PTFE surface. 